\title{
Protocol
}

\section{Indirect Immunometric ELISA}

\author{
Thomas O. Kohl and Carl A. Ascoli
}

This assay facilitates the immunometric determination of assay-associated reagents including the capture and detection antibodies as well as the analyte (i.e., antigen or antibody). It can precede the development of a sandwich enzyme-linked immunosorbent assay (ELISA) in which optimal antibody concentrations are applied for the quantitative measurement of the antigen. This protocol describes the materials and equipment required for the measurement of chromogenic substrate development; however, it can be adapted for use with chemiluminescent- and fluorescent-labeled reporters.

\section{MATERIALS}

It is essential that you consult the appropriate Material Safety Data Sheets and your institution's Environmental Health and Safety Office for proper handling of equipment and hazardous material used in this protocol.

RECIPES: Please see the end of this protocol for recipes indicated by $<R>$. Additional recipes can be found online at http://cshprotocols.cshlp.org/site/recipes.

Reagents

3,3' $5,5^{\prime}$-tetramethylbenzidine (TMB) (Rockland Immunochemicals, \#TMBE-1000)

(for HRP-based assays)

Antibodies of known concentration

Antibody diluent solution (1\% [v/v] fish gel [Sigma-Aldrich, \#G7765] in PBS or TBS)

Antibody, enzyme-labeled antihost, and dilution buffer (e.g., Rockland Immunochemicals,

\#MB-061-100 or \#MB-076-0100)

Antigen(s)

Blocking buffer $(3 \%[\mathrm{w} / \mathrm{v}]$ fish gel in PBS or TBS)

Carbonate buffer for immunoassays $<\mathrm{R}>$ (optional; see Step 1)

para-Nitrophenyl phosphate (pNPP) (Rockland Immunochemicals, \#NPP-10) (optional; for alkaline phosphatase [AP]-based assays)

Phosphate-buffered saline (PBS) for immunoassays ( $\mathrm{pH} 7.4)<\mathrm{R}>$ (optional; see Step 1)

Stop solution $(1 \mathrm{M} \mathrm{HCl})$ (for horseradish peroxidase [HRP]-based assays only; see Step 11)

Tris-buffered saline (TBS) for immunoassays $<\mathrm{R}>$ (optional; see Step 1)

Wash buffer with detergent (PBS or TBS containing 0.05\% [v/v] Tween 20)

Equipment

Microplate reader (Bio-Rad, Model \#680) with Microplate Manager Software (5.2.1) or equivalent Microplate sealing tape, polyester, nonsterile (Corning, \#4612 or equivalent)

Microtiter plates (flat bottom, 96 -well, $0.3 \mathrm{~mL} /$ well) with appropriate surface chemistry

(e.g., Immulon 4 HBX; Thermo Scientific, \#3855 or equivalent)

From the Antibodies collection, edited by Edward A. Greenfield.

(C) 2017 Cold Spring Harbor Laboratory Press

Cite this protocol as Cold Spring Harb Protoc; doi:10.1101/pdb.prot093708 
Multichannel pipettes (eight- or 12-channel) (Costar, \#4888 or equivalent)

Plate washer (Dynex Ultrawash PLUS or equivalent)

Reagent reservoirs (VWR, \#12577-027 or equivalent)

1. Dilute the antigen to a final concentration of $1 \mu \mathrm{g} / \mathrm{mL}$ for protein or $0.1 \mu \mathrm{g} / \mathrm{mL}$ for peptides in PBS, carbonate buffer, or TBS. Coat the wells of a microtiter plate by pipetting $100 \mu \mathrm{L}$ of the antigen dilution into individual wells of the plate.

For HRP conjugates, use PBS or carbonate buffer. For AP conjugates use TBS.

2. Cover the plate with a lid or microtiter plate sealer. Incubate for $1 \mathrm{~h}$ at room temperature or overnight at $2^{\circ} \mathrm{C}-8^{\circ} \mathrm{C}$.

Depending on the antigen, coating incubation lengths might have to be optimized.

3. Using a plate washer, aspirate the coating solution. Wash the plate three times by filling each well with $300 \mu \mathrm{L}$ of wash buffer containing detergent. Remove retained liquid by patting the plate on a paper towel.

4. Add $200 \mu \mathrm{L}$ of $3 \%$ (v/v) fish gel in PBS or TBS blocking buffer to block remaining protein-binding sites. Incubate for $1 \mathrm{~h}$ at room temperature or $30 \mathrm{~min}$ at $37^{\circ} \mathrm{C}$.

5. Aspirate the blocking solution using the plate washer. Wash the plate as described in Step 3.

6. Dilute the antibody to $1 \mu \mathrm{g} / \mathrm{mL}$ in $1 \%$ (v/v) fish gel in PBS or TBS. Add $100 \mu \mathrm{L}$ to the wells in Column 1 . Titrate the antibody by serial dilution across the length of the plate. Incubate for $1 \mathrm{~h}$ at room temperature.

Antibody blanks and assay blanks do not receive any antibody solution.

7. Using the plate washer, aspirate the antibody solution. Wash the plate three times by filling each well with $300 \mu \mathrm{L}$ of wash buffer containing detergent. Remove the retained liquid by patting the plate on a paper towel.

8. Prepare enzyme-labeled antihost antibody at a recommended dilution of 1:20,000 using the dilution buffer provided with the antibody. Add $100 \mu \mathrm{L}$ of the enzyme-conjugated secondary antibody to each well, including the assay control wells. Incubate for $30 \mathrm{~min}$ at $37^{\circ} \mathrm{C}$.

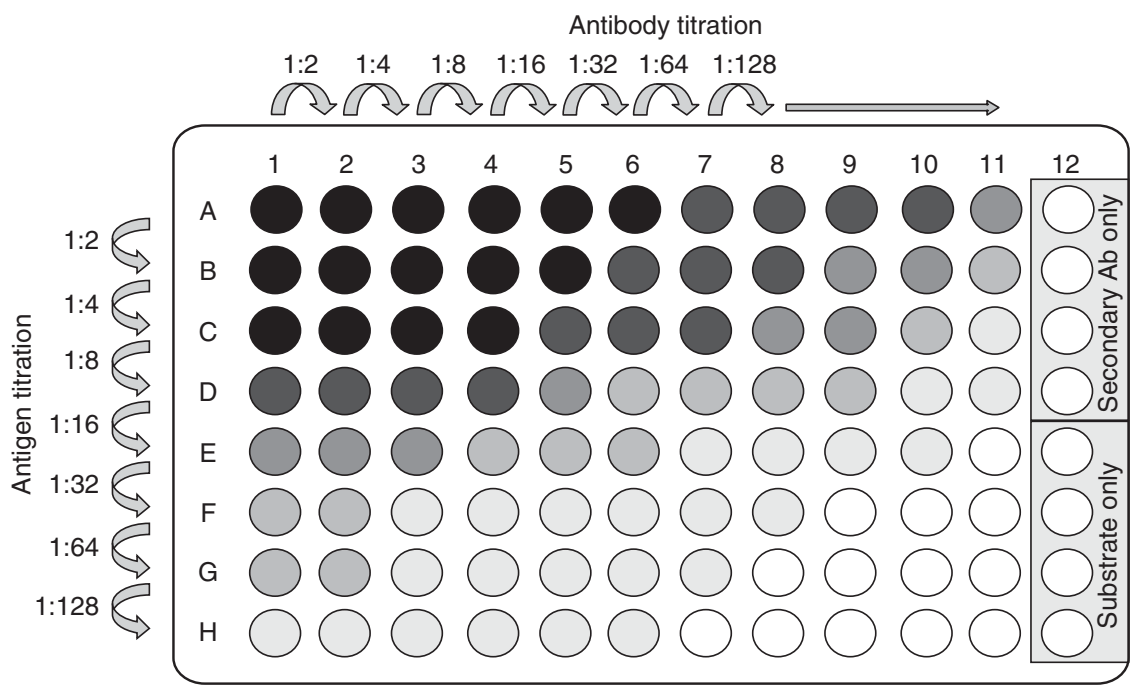

FIGURE 1. Antibody-antigen checkerboard titration format. 


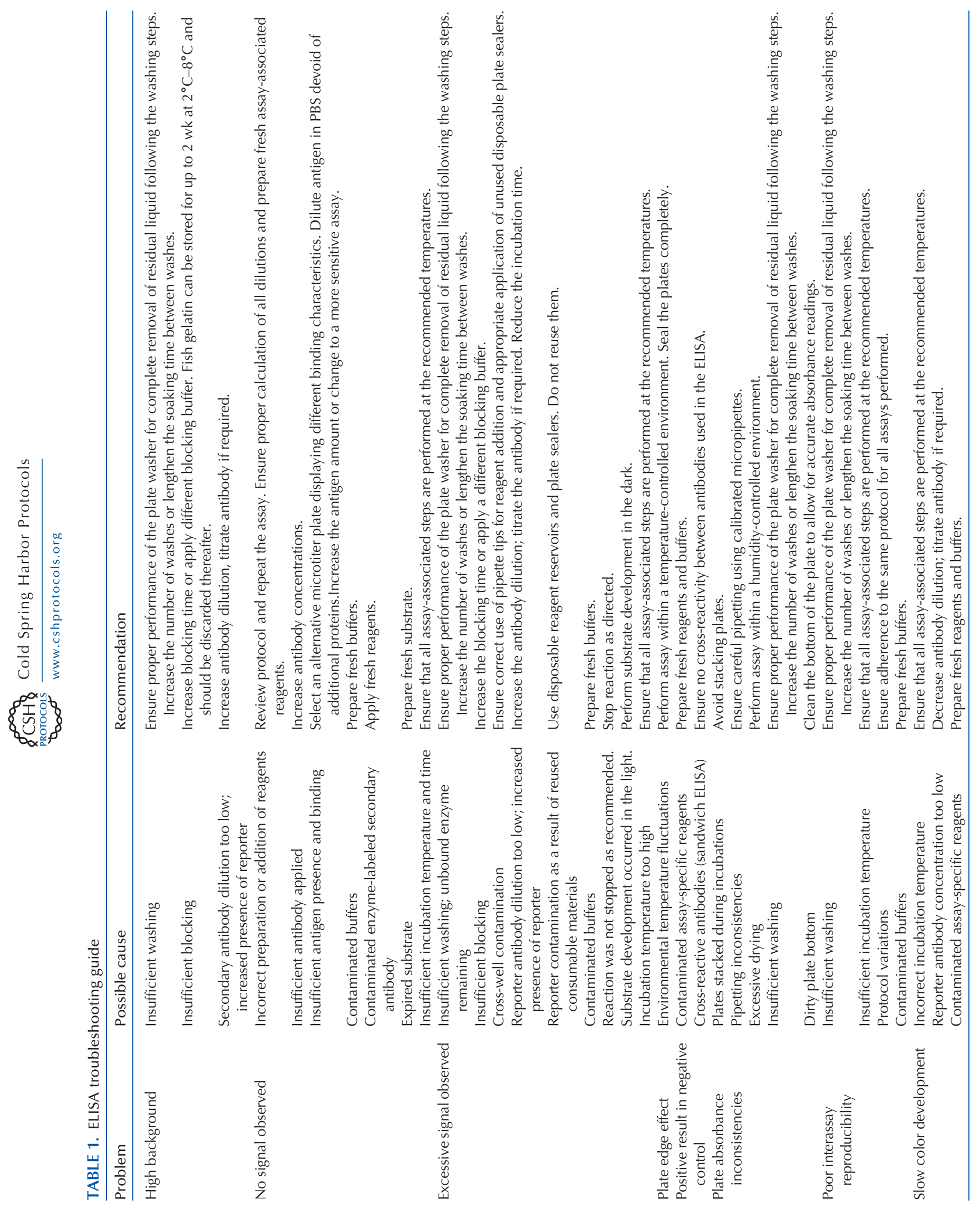


A 1:20,000 dilution of the reporter-labeled antibody is a recommendation only and is dependent on the concentration of the reporter antibody. It is best to titrate the antibody by indirect ELISA using the checkerboard titration format (Fig. 1) to determine the optimal working concentration.

9. Using the plate washer, aspirate the secondary antibody solution. Wash the plate three times as described in Step 3.

10. Prepare or equilibrate the substrate solution (TMB for HRP or pNPP for AP) to room temperature. Add $100 \mu \mathrm{L} /$ well to each well. Incubate the enzyme-based reactions for $30 \mathrm{~min}$ at room temperature in the dark.

Avoid introducing air bubbles when adding substrate to the wells, because these will affect the absorbance readings.

11. Stop the HRP reactions by adding $100 \mu \mathrm{L}$ of $1 \mathrm{M} \mathrm{HCl}$ per well. Alkaline phosphatase-based substrate development does not require a stopping reagent.

For further quantification of low-level reactions, skip Step 11 and perform plate measurements at set time intervals.

12. Read the plates on a microplate reader set to $405 \mathrm{~nm}$ for AP-based and $450 \mathrm{~nm}$ for HRP-based substrate development.

Please see Table 1 for a detailed troubleshooting guide.

The main objectives during the development of an ELISA are (1) to achieve the optimal signal-tonoise ratio for the desired sensitivity of the assay, (2) to ensure the reproducibility of the assay for the analyte at hand, and (3) to facilitate accurate measurement of the analyte within the dynamic range of the assay. The signal-to-noise ratio of an assay is defined as the signal obtained in the presence of analyte in comparison to the signal obtained in the absence of analyte. An overall increase in signalto-noise ratio ensures assay suitability for the detection of smaller amounts of antigen present in biological samples.

During the development of an immunometric ELISA for a specific application, individual assay component concentrations can vary widely. To establish optimal working concentrations of reagents used in the assay, titration of individual assay components is recommended. Termed checkerboard titrations (Fig. 1), these experiments allow for the variation of assay reagents in a single experiment, yielding insight into the optimal reagent concentrations to be applied in the assay.

Titration of assay components by indirect ELISA-for example, an antibody to be used in the development of a sandwich ELISA-requires the absorption of antigen onto the plate. Whereas reporter-labeled secondary antibody concentrations are kept constant, antigen and antibody are generally applied in excess starting at a recommended concentration of $1 \mu \mathrm{g} / \mathrm{mL}$ per well before being titrated by dilution. This results in the titration pattern shown in Figure 1 and allows for determination of an optimal antibody concentration to be used in the assay. Similarly, this can be performed for multiple antibodies intended for the development of a sandwich ELISA.

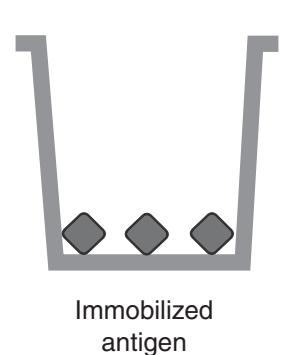

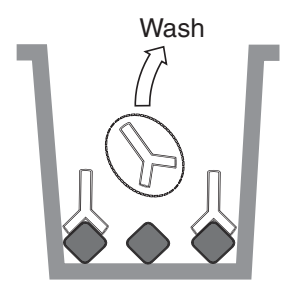

Primary antibody

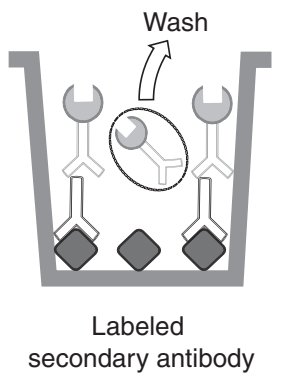

Substrate addition, signal detection, and quantification

FIGURE 2. Indirect ELISA for the colorimetric detection of antigen-specific antibodies. 
TABLE 2. Indirect ELISA for the analysis of sera

\begin{tabular}{lccccccccccc}
\hline & \multicolumn{10}{c}{ Test sample dilution } \\
\cline { 2 - 10 } Donor & $1 / 100$ & $1 / 300$ & $1 / 900$ & $1 / 2700$ & $1 / 8100$ & $1 / 24,300$ & $1 / 72,900$ & $1 / 21,8700$ & $1 / 65,6000$ & $2^{\prime}-\mathrm{Ab}$ only & Blank \\
\hline$\# 1$ & 4.000 & 4.000 & 4.000 & 4.000 & 3.642 & 2.256 & 1.052 & 0.467 & 0.232 & 0.096 & 0.056 \\
$\# 2$ & 3.935 & 4.000 & 3.982 & 4.000 & 3.805 & 3.038 & 1.675 & 0.787 & 0.391 & 0.088 & 0.054 \\
$\# 3$ & 3.995 & 3.725 & 3.078 & 1.922 & 1.141 & 0.609 & 0.325 & 0.185 & 0.136 & 0.096 & 0.056 \\
$\# 4$ & 4.000 & 4.000 & 4.000 & 3.968 & 3.444 & 2.249 & 1.056 & 0.538 & 0.279 & 0.099 & 0.054 \\
$\# 5$ & 3.915 & 3.893 & 4.000 & 4.000 & 3.882 & 3.369 & 1.984 & 0.950 & 0.441 & 0.102 & 0.060 \\
Negative control & 0.216 & 0.202 & 0.178 & 0.201 & 0.209 & 0.138 & 0.111 & 0.103 & 0.106 & 0.112 & 0.065 \\
\hline
\end{tabular}

The indirect ELISA necessitates the abundant availability of purified antigen. In brief, detection of specific antibodies is facilitated by the coating of microtiter plates with specific antigen followed by the incubation of diluted test bleed or undiluted supernatant samples (Fig. 2). Washing steps incorporated into the procedure allow for the removal of unbound antibodies and endogenous protein contained within the samples, before incubation with a reporter-labeled secondary antibody. Alternatively a reporter-conjugated Protein A or G can be used instead of a species-specific antiimmunoglobulin antibody. An additional washing step ensures the removal of unbound reporterlabeled secondary antibody before addition of substrate. Enzymatic hydrolysis of the substrate results in the color development, a process that can be visually observed and measured using a microplate reader.

All antigens being assayed are contained in a complex solution known as the "matrix." If target analytes are not of high purity, ELISAs are sometimes prone to the matrix effect in which an inaccurate result is achieved because of inhibition of full analyte recovery from within the matrix sample. The matrix can be simple (PBS) or complex (serum); however, the more complex the matrix, the more likely a matrix effect will be encountered.

The indirect ELISA is particularly useful for the identification as well as quantification of specific antibodies contained in antiserum test bleeds or hybridoma supernatant. Analysis typically involves serial dilution of the antibody when it is contained in serum samples, whereas supernatants are usually analyzed in undiluted form. Plates are coated with a predetermined optimal concentration of antigen before threefold titration of test samples, as shown in Table 2.

The titration curves of individual donor samples so assayed decrease in absorbance over the course of sample dilution (Fig. 3). Repeated antiserum analyses over the course of an antibody generation study helps identify the host's antibody-mediated immune response against the antigen and aids in the selection of animals for monoclonal antibody development.

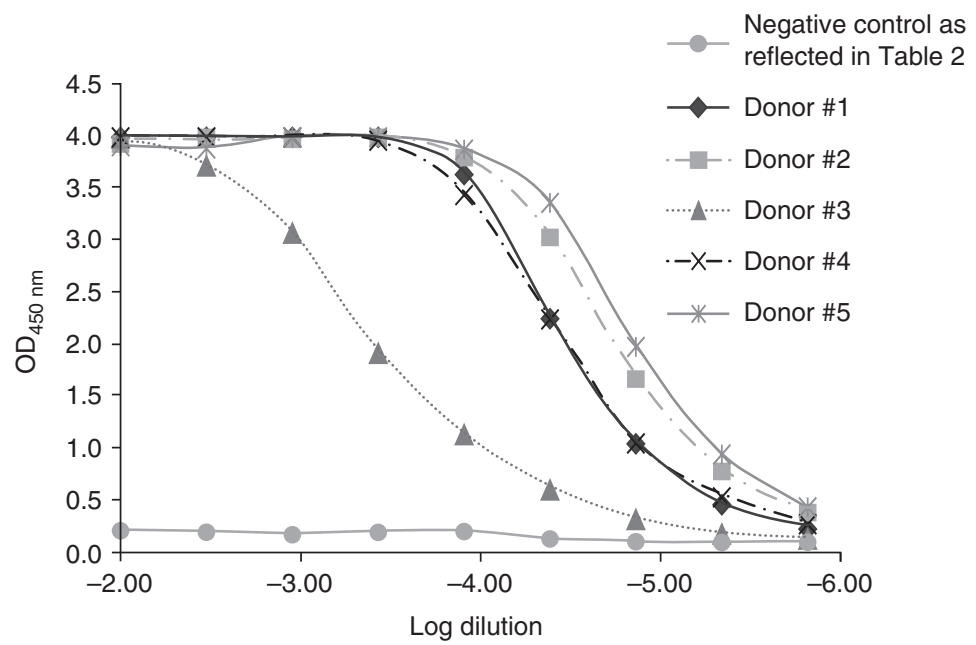

FIGURE 3. ELISA-based analysis of serially diluted antiserum from different donors. 
TABLE 3. Indirect ELISA-based hybridoma supernatant analysis

\begin{tabular}{|c|c|c|c|c|c|c|c|c|c|c|c|c|}
\hline & 1 & 2 & 3 & 4 & 5 & 6 & 7 & 8 & 9 & 10 & 11 & 12 \\
\hline A & 3.828 & 0.076 & 1.755 & 0.096 & 0.184 & 0.178 & 3.774 & 3.766 & 3.983 & 0.309 & 0.620 & 0.350 \\
\hline B & 3.949 & 3.591 & 3.817 & 0.527 & 0.254 & 0.257 & 0.215 & 0.240 & 3.733 & 3.956 & 4.000 & 4.000 \\
\hline C & 3.211 & 0.651 & 0.985 & 2.761 & 0.132 & 3.182 & 3.518 & 2.585 & 3.721 & 0.217 & 3.859 & 3.768 \\
\hline D & 1.217 & 3.906 & 3.677 & 4.000 & 0.224 & 3.640 & 3.787 & 1.212 & 3.580 & 4.000 & 0.203 & 0.336 \\
\hline$E$ & 0.829 & 3.693 & 3.745 & 3.691 & 0.107 & 3.829 & 0.401 & 0.358 & 0.171 & 3.819 & 1.799 & 3.881 \\
\hline $\mathrm{F}$ & 0.445 & 3.694 & 0.251 & 1.317 & 0.271 & 0.210 & 1.767 & 3.805 & 3.661 & 0.450 & 3.274 & 3.793 \\
\hline G & 0.237 & 3.874 & 0.232 & 0.261 & 0.376 & 0.992 & 0.281 & 3.834 & 3.889 & 0.622 & 0.280 & 0.239 \\
\hline $\mathrm{H}$ & 0.071 & 4.000 & 3.888 & 0.223 & 3.986 & 3.841 & 0.214 & 3.817 & 2.535 & 0.153 & 0.165 & 0.141 \\
\hline
\end{tabular}

The different shades of gray aid in the selection of the clones with highest to lowest antigen-specific reactivity. Typically clones showing a $>3 \times$ background reactivity are chosen, from which clones displaying the highest reactivity are chosen for subcloning purposes first.

Similarly, the indirect ELISA is used for analyzing hybridoma supernatants. Microtiter plates are coated with a predetermined optimal antigen concentration before adding $50 \mu \mathrm{L}$ of tissue culture supernatant containing hybridoma-secreted antigen-specific antibody. The addition of reporter-labeled secondary antibody and substrate results in substrate hydrolysis that on spectrophotometric measurement yields results similar to those shown in Table 3. Included in the hybridoma supernatant analysis is a fivefold serial dilution of the last test bleed from the host selected for fusion purposes. This positive control is in Column 1 in the indirect ELISA. TMB substrate hydrolysis by the HRP-labeled secondary antibody results in the identification of individual antigen-specific hybridoma cells as indicated by varying shades of gray, which aids in the selection of clones for expansion and subcloning.

Carbonate Buffer for Immunoassays

\begin{tabular}{ll} 
Reagent & Amount per 1 L of solution \\
\hline $\mathrm{Na}_{2} \mathrm{CO}_{3}$ & $1.59 \mathrm{~g}$ \\
$\mathrm{NaHCO}_{3}$ & $2.93 \mathrm{~g}$ \\
Adjust to pH 9.5 using $1 \mathrm{~N} \mathrm{NaOH}$. Store at ambient temperature.
\end{tabular}

Phosphate-Buffered Saline (PBS) for Immunoassays ( $p H$ 7.4)

\begin{tabular}{ll} 
Reagent & Amount per 1 L of solution \\
\hline $\mathrm{NaCl}$ & $8 \mathrm{~g}$ \\
$\mathrm{KCl}$ & $0.2 \mathrm{~g}$ \\
$\mathrm{Na}_{2} \mathrm{HPO}_{4}$ & $1.44 \mathrm{~g}$ \\
$\mathrm{KH}_{2} \mathrm{PO}_{4}$ & $0.24 \mathrm{~g}$
\end{tabular}

Store at ambient temperature.

Tris-Buffered Saline (TBS) for Immunoassays

\begin{tabular}{ll} 
Reagent & Amount per 1 L of solution \\
\hline $\mathrm{NaCl}$ & $8 \mathrm{~g}$ \\
$\mathrm{KCl}$ & $0.2 \mathrm{~g}$ \\
Tris- $\mathrm{HCl}$ & $3 \mathrm{~g}$ \\
Adjust to pH 7.6 using $1 \mathrm{~N} \mathrm{NaOH}$. Store at ambient temperature.
\end{tabular}




\section{Indirect Immunometric ELISA}

Thomas O. Kohl and Carl A. Ascoli

Cold Spring Harb Protoc; doi: 10.1101/pdb.prot093708

\begin{tabular}{|c|c|}
\hline $\begin{array}{r}\text { Email Alerting } \\
\text { Service }\end{array}$ & Receive free email alerts when new articles cite this article - click here. \\
\hline $\begin{array}{l}\text { Subject } \\
\text { Categories }\end{array}$ & $\begin{array}{l}\text { Browse articles on similar topics from Cold Spring Harbor Protocols. } \\
\text { Antibodies (119 articles) } \\
\text { Antibodies, general (289 articles) } \\
\text { Immunoassay ( } 26 \text { articles) }\end{array}$ \\
\hline
\end{tabular}

